\title{
Preparation of Building Materials from Coke-chemical Resin
}

\author{
N.T. Smagulova ${ }^{1,}$, ${ }^{\text {, Zh.K. Kairybekov }}{ }^{1, \text { b }}$, A.K. Kairybekov ${ }^{1, \mathrm{c}}$ \\ ${ }^{1}$ Al-Farabi Kazakh National University, Almaty, Kazakhstan \\ ${ }^{1}$ Scientific research institute of new chemical technologies and materials, Almaty, Kazakhstan \\ aemail: nazym2011@inbox.ru
}

Keywords: Bitumen; Coke-chemical resin; Hydrocarbon

\begin{abstract}
A systematic study of the primary tar produced by Shubarkol coal distillation was conducted initially and demonstrated that it can be used to produce road and construction bitumen. Oxidation of coke-chemical tar allowed determining the optimum conditions (temperature and time) of the process, possibility of road and construction bitumen production that meets physical and chemical parameters of grades BND 130/200 and BN 70/30. Oxidation demonstrated that the quantity of total hydrocarbon will be reduced by 19 per cent, and the quantity of asphaltene will be increased by 29.88 per cent. Reduction of hydrocarbons during oxidation demonstrates the formation of tar and asphaltene. Shubarkol coal distillation demonstrated that coke-chemical tar is a potential raw material for bitumen production as a petroleum raw material.
\end{abstract}

\section{Introduction}

Despite the abundance of reserves of high viscosity oil, a problem of providing production with bitumen remains a key issue in the Republic of Kazakhstan. On the one hand, research compliant with the standards of bitumen physical-mechanical characteristics and beneficial use of bitumen resin compositions after the coking of coal ensures demand for bitumen, and on the other hand, it provides with an opportunity to solve environmental problems in coal refinery areas [1].

The increased demand for petroleum products and environmentally friendly high-quality chemical products requires advanced processing. Therefore, the practical value of application of new efficient catalytic processes is very high due to the increase of output, quality of engine fuel produced from coke-chemical tar and production of high-quality products from processed wastes. Demand for high quality products requires designing a simple and efficient technology. Notwithstanding the fact that a number of scientific works have been published in the area to date, no technology for processing of coke-chemical tar and integral processing for efficient application of processed wastes has been designed.

Since coke-chemical tar is normally produced from condensed aromatized hydrocarbons and other high molecular weight compounds, it is the source of hardly processed raw materials. First of all, tar is dehydrated, divided into individual fractions using alkali, acid extraction, crystallization, hydrotreatment of fractions to produce benzol, naphthalene, phenol, pyridine bases and other chemical products.

Therefore, the practical value of bitumen and bitumen material production from coke-chemical tar is very high.

\section{Experiments}

Process of oxidation of residues of oil is widely used in the production of high-quality road and construction bitumen possessing special rheological and functional properties. We carried out the oxidation of residues of «charcoal oil» by means of passing through $1 \mathrm{~kg}$ of sources of $1.4 \mathrm{~m}^{3}$ of air on the laboratory setup in periodic regime at $220^{\circ} \mathrm{C}$ during five hours (Figure 1). 


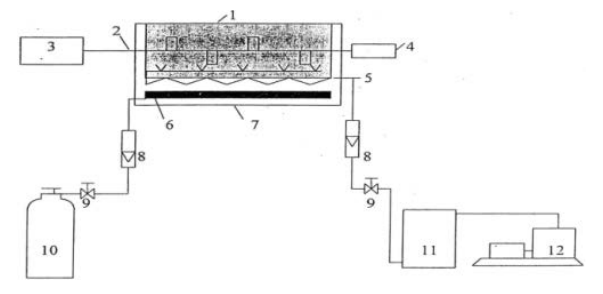

1 - reactor; 2 - bubbler; 3 - drive; 4 - enforcing setup; 5 - air transfer tube; 6 - heater;

7 - external closing; 8 - rotameter; 9 - valve regulator; 10 - container (balon) with propanebutane mixture; 11 - receiver; 12 - compressor

Figure 1 - Experimental setup for oxidation of residues of «charcoal oil»

\section{Results and Discussion}

In the process of bitumen preparation, coke-chemical resin was researched. It is produced through the devolatilization process of coal from Shubarkol mine as a potential sourceof raw material. Since the connection of metals (Mo, Sn, Zn, Co, Ni, Ti, Mn, Fe) with constant and variable valency in addition to organic substances is a catalyst, a mass-spectral analysis was conducted in order to increase the effectiveness of bitumen preparation process, as well as to determine the percentage of impurity elements in the composition of the raw materials for research.

The results of the mass-spectral analysis are shown in Table 1.

Table 1-Spectral analysis of primary resin

\begin{tabular}{|c|c|c|c|}
\hline Composition & Primary resin & Composition & Primary resin \\
\hline $\mathrm{Sr}$ & - & $\mathrm{Ag}$ & - \\
\hline $\mathrm{Co}$ & - & $\mathrm{Zr}$ & - \\
\hline $\mathrm{Sn}$ & - & $\mathrm{Be}$ & 0.0002 \\
\hline $\mathrm{Y}$ & - & $\mathrm{Bi} \cdot 10^{-4}$ & - \\
\hline $\mathrm{Cu}$ & 0.0002 & $\mathrm{Asx} 10^{-3}$ & 0.002 \\
\hline $\mathrm{Zn}$ & - & $\mathrm{P}^{-102} \cdot$ & 0.25 \\
\hline $\mathrm{Mo}$ & - & $\mathrm{CaO}$ & $<0,1$ \\
\hline $\mathrm{Ba}$ & 0.03 & $\mathrm{MgO}$ & 0.2 \\
\hline $\mathrm{Ni}$ & 0.002 & $\mathrm{Fe2O3}$ & 0.06 \\
\hline $\mathrm{Mn}$ & 0.008 & $\mathrm{SiO} 2$ & $<0,01$ \\
\hline $\mathrm{V}$ & - & $\mathrm{Ai2} \mathrm{O} 3$ & $<0,5$ \\
\hline $\mathrm{Ti}$ & 0.006 & $\mathrm{~K} 2 \mathrm{O}$ & $<0,1$ \\
\hline $\mathrm{Pb}$ & 0.0015 & $\mathrm{Na} 2 \mathrm{O}$ & \\
\hline
\end{tabular}

As it is seen from the table, a large amount of metal and its compounds, which serve as catalysts, is concentrated in the composition of primary resin. In preparation of bitumen compliant with the requirements of the standard, an important role is played by the right choice of a technological process, in which the major attention is paid to the properties of raw materials. A widespread technological row in the process of bitum preparation includes: oxidation of raw materials on discrete and indiscrete devices, tubular reactors, oxidation columns; use of asphalt-resin materials, obtained by deasphalting hydrocarbon; and linking petroleum products of different properties and content for getting specific grades of bitumen. A rational technology among them is an oxidation technology used on discrete devices, which is commonly used.

Inasmuch fresh raw material proved to be suitable for bitumen production by hydrocarbon type content, an oxidation process was carried out at the temperature of $24^{0} \mathrm{C}$ and air flow of $1.5 \mathrm{~m}^{3} / \mathrm{min}$ during the period of 6 hours. Due to requirements discrepancy of physical-mechanical characteristics of received products during the oxidation process to standards for architectural oil bitumen, in order to identify of the reason its hydrocarbon type composition was identified. 
Table 2 - Hydrocarbon type composition of oxidized products at the temperature of $24^{0} \mathrm{C}$

\begin{tabular}{|l|c|}
\hline Composition & Wt. $\%$ \\
\hline hydrocarbons: & 17.01 \\
\hline paraffin-naphtene & 14.77 \\
\hline monocyclic aromatic & 0.84 \\
\hline dicyclic aromatic & 0.63 \\
\hline condensed polycyclic aromatic & 0.77 \\
\hline Resin: & 22.01 \\
\hline petroleum-benzol resin & 4.72 \\
\hline benzol- resin & 0.34 \\
\hline aethanolum-benzol resin & 16.95 \\
\hline Asphaltene & 45.00 \\
\hline Polycarbon, carboid & 15.98 \\
\hline Total volume: & 100 \\
\hline
\end{tabular}

As the Table shows, the product composition contains: resin- 22.01 wt. \%, hydrocarbons- 17, 01 wt. \%, asphaltene 45.0 wt. \%, polycarbon, carboid 15.98 wt. \%. Compared to the fresh raw material, the amount of asphaltene increased from 15.84 wt.\% to $45.0 \mathrm{wt}$. \%. High content of asphaltene in bitumen composition leads to disruption of its structure. Decrease in the volume of paraffin-naphthene hydrocarbons from 26,27 wt.\% to 14,77 wt. \% can be attributed to the vector changes occurring during the oxidation process of pentane $\leftrightarrow \mathrm{MA} \leftrightarrow \mathrm{BCAA} \leftrightarrow \mathrm{PCA} \leftrightarrow \mathrm{C} \leftrightarrow \mathrm{Ac} \rightarrow$ K.

During the process of bitumen structural rupture, level of molecules condensing leads to the decrease of dispersed phase volume and increase of high molecular weight part with the increase of side chain rupture.

Due to the high content of oxygen-containing substances in the form of hydroxyl and carbonyl groups in the composition of resin high-molecular fractions, low-temperature oxidation process is rational for the synthesis of asphaltene by applying condensation reactions of oxygen compounds [5]. Therefore, the oxidation of raw materials was underway at a temperature of $160 \mathrm{C}^{0}$, air flow of $1.5 \mathrm{~m} 3 / \mathrm{min}$. during the period of 3 hours. The sample was retrieved every 30 minutes and its physical-mechanical characteristics were determined. In 30 minutes, physical-mechanical characteristics did not fully comply with the requirements of the standard. Physical-mechanical characteristics of products were identified after conducting oxidative process for 90 minutes (table 3).

Table 3 - Physical-mechanical characteristics of products after conducting oxidative process for 90 minutes

\begin{tabular}{|c|c|c|c|}
\hline Characteristics: & products & $\begin{array}{l}\text { Bitumen grade } \\
\text { BND130/200 }\end{array}$ & Testing methodology \\
\hline $25^{\circ} \mathrm{C}$, needle penetration depth $0,1 \mathrm{~mm}$ & 190 & $131-200$ & GOST11501 \\
\hline $\begin{array}{l}\text { Melting point on Bowl and ring, }{ }^{\circ} \mathrm{C} \text { is not } \\
\text { low }\end{array}$ & 43 & 40 & GOST11506 \\
\hline $\begin{array}{l}\text { Brittleness temperature, } \\
{ }^{\circ} \mathrm{C} \text { not low }\end{array}$ & -18 & -18 & GOST11507 \\
\hline Penetration index & \multicolumn{2}{|c|}{+2.1} & \multirow{2}{*}{ GOST 22245} \\
\hline Ductility interval & \multicolumn{2}{|c|}{$57 \sim 77^{\circ} \mathrm{C}$} & \\
\hline
\end{tabular}

As seen from the table, the amount of bitumen penetration is equal to $190 \mathrm{~mm}$. Since this value of BND 130/200 bitumen penetration is within the interval for viscous road petroleum bitumen (131-200 mm), products of BND 130/200 grade derived from the heavy still bottoms of cokechemical resins fall into the category of viscous road petroleum bitumen. Its melting temperature and brittleness temperature fully comply with the requirements of the standard. Penetration index is 
+2.1 .

By its rheological properties and deformation characteristics, viscous road petroleum bitumen, which corresponds to the penetration index, whose gel structure corresponds to its rheological state, belongs to group 3 of bitumen [6;7]. Its ductility interval equals $57 \sim 77^{\circ} \mathrm{C}$. Since the numerical value interval of the ductility interval is wide, deformation capacity of bitumen is high; thus it can resist splitting at low and high temperatures of the environment. The chemical group composition of the produced road petroleum bitumen BND 130/200 (table 3) was defined.

Table 4 - Chemical group composition of the produced road petroleum bitumen BND 130/299

\begin{tabular}{|l|c|}
\hline Composition & volume, weight \% \\
\hline Hydrocarbons: & 44.68 \\
\hline paraffin-naphtene & 5.00 \\
\hline monocyclic aromatic & 11.86 \\
\hline dicyclic aromatic & 13.60 \\
\hline condensed polycyclic aromatic & 14.22 \\
\hline Resin: & 30.50 \\
\hline Petroleum-benzol resin & 7.00 \\
\hline benzol- resin & 11.99 \\
\hline aethanolum-benzol resin & 11.51 \\
\hline Asphaltene & 23.00 \\
\hline Polycarbon, carboid & 1.82 \\
\hline Total volume: & 100 \\
\hline
\end{tabular}

As the Table shows, the composition of petroleum bitumen BND130/200 contains: resin- 30.50 wt. \%, hydrocarbons- 44,68 wt. \%, asphaltene -23.00 wt. \%, polycarbon, carboid 1.82 wt. \%. As the volume of paraffin-naphthenic hydrocarbons in the composition of primary resin is high (26.72 wt.\%), the volume of these hydrocarbons decreases during the oxidation process as a result of asphalthenes development. The chemical group composition of the products produced during the oxidation process in section of 120 and $150 \mathrm{~min}$ is shown in table 5.

Table 5 - Chemical group composition of oxidized production

\begin{tabular}{|l|c|c|}
\hline \multirow{2}{*}{ Fraction } & \multicolumn{2}{|c|}{ Volume } \\
\cline { 2 - 3 } & Wt. \% & Wt. \% \\
\cline { 2 - 3 } & 120 minutes & 150 minutes \\
\hline Hydrocarbons: & 15.50 & 20.44 \\
\hline paraffin-naphtene & 7.69 & 3.68 \\
\hline monocyclic aromatic & 1.56 & 1.19 \\
\hline dicyclic aromatic & 1.54 & 9.31 \\
\hline condensed polycyclic aromatic & 4.71 & 6.26 \\
\hline Resin: & 30,05 & 26,96 \\
\hline Petroleum-benzol resin & 5.39 & 1.0 \\
\hline benzol- resin & 7.1 & 10.07 \\
\hline aethanolum-benzol resin & 17.59 & 15.89 \\
\hline Asphaltene & 18.57 & 17.39 \\
\hline Polycarbon, carboid & 35.88 & 35.21 \\
\hline Total volume & 100 & 100 \\
\hline
\end{tabular}


As the Table shows, the composition of oxidized products within 120 minutes contains: hydrocarbons- 15.50 wt. \%, resin - 30.05 wt. \%, asphaltene - 18.57 wt. \%. And in the composition of oxidized products within 150 minutes there are: hydrocarbons- 20,44 wt. \%, resin - 29,96 wt. \%, asphaltene - 17,39 wt. \%. Compared to primary resin, the volume of polycarbon (35.88 wt. \%) and carboid (35.21 wt. \%) is higher.

In turn, the volume of polycarbon and carboid as the original raw material with the aroma of substantial coke-chemical resin has increased due to the changes that at the same time reduce the volume of hydrocarbon fraction.

Also, physical-mechanical characteristics of products were identified after conducting oxidative process for 180 minutes (table 6).

Table 6 - Physical-mechanical characteristics of products after conducting oxidative process for 180 minutes

\begin{tabular}{|l|c|c|c|}
\hline Characteristics: & products & $\begin{array}{c}\text { Bitumen grade } \\
\text { BN70/30 }\end{array}$ & $\begin{array}{c}\text { Testing } \\
\text { methodology }\end{array}$ \\
\hline $25^{\circ} \mathrm{C}$, needle penetration depth 0,1 mm & 21 & $21-40$ & GOST11501 \\
\hline Melting point on Bowl and ring, ${ }^{\circ} \mathrm{C}$ is not low & 70 & $70-80$ & GOST11506 \\
\hline Penetration index & \multicolumn{2}{|c|}{+0.80} & GOST 22245 \\
\hline
\end{tabular}

As seen from the table, the amount of bitumen penetration is equal to $21 \mathrm{~mm}$. As the amount of BN70/30 penetration received is included in the interval of penetration value of construction bitumen (21-40 mm), BN70/30 bitumen produced from resin can be classified as construction bitumen. Its melting temperature $\left(70^{\circ} \mathrm{C}\right)$ fully complies with the requirements of the standard. Penetration index eguals +0.8 . Construction bitumen BN70/30, which indicates the colloidal degree of bitumen or a deviation from its fixed viscous state, falls into a group of bitumen whose rheological state according to the penetration index is sol-gel structural.

The modification of bitumen standards through an increase of oxidation period shows the mechanism of oxidation. High volume of oxygen-containing compounds (hydrocarbons 17,1 wt. \%) in the composition of BND 130/200 bitumen, produced within 90 minutes, is attributed to the fact that the process goes through the grade of peroxide development. And with the increase in oxidation time, the following type of reaction prevails:

$$
\begin{gathered}
\mathrm{RH}+\mathrm{O}_{2} \rightarrow \mathrm{R}^{\cdot}+\mathrm{HOO} \cdot \\
\mathrm{R}_{1}+\mathrm{R}_{2} \mathrm{H} \rightarrow \mathrm{HR}_{1} \mathrm{R}_{2} \cdot+\mathrm{R}_{3} \mathrm{H} \rightarrow \mathrm{HR}_{1} \mathrm{HR}_{2}+\mathrm{R}_{3} \cdot
\end{gathered}
$$

Chemical group composition of bitumen prepared is shown in Table 7.

Table 7 - Chemical group composition of construction bitumen BN 70/30

\begin{tabular}{|l|c|}
\hline \multirow{2}{*}{ Composition } & Volume \\
\cline { 2 - 2 } & wt. \% \\
\hline \multirow{2}{*}{ Hydrocarbons: } & 19.47 \\
\hline paraffin-naphthenic hydrocarbons & - \\
\hline monocyclic aromatic hydrocarbons & 2.08 \\
\hline bicyclic aromatic hydrocarbons & 1.16 \\
\hline condensed polycyclic aromatic hydrocarbons & 16.67 \\
\hline Resin: & 29.45 \\
\hline Petroleum-benzol resin & 0.61 \\
\hline benzol- resin & 8.20 \\
\hline aethanolum-benzol resin & 21.20 \\
\hline Asphaltene & 29.88 \\
\hline Polycarbon, carboid & 21.00 \\
\hline Total volume & 99.80 \\
\hline
\end{tabular}


As the Table shows, the product composition contains: resin- 29.45 wt. \%, hydrocarbons- 19, 47 wt. \%, asphaltene - 29.88 wt. \%, polycarbon, carboid 21.00 wt. \%.

\section{Conclusions}

The study identified the optimal states of coke-chemical resin oxidation process (temperature, time) and specified a possibility to prepare road construction bitumen of standards with physicalmechanical indicators BND 130/200 and BN 70/30, BN 90/10.

\section{Acknowledgement}

Work is funded by MES RK grant on a priority 5.1. Basic studies are carried out in the field of natural sciences according to the program 'To develop the scientific basis of processing of combustible minerals and preparation of new materials'.

\section{References}

[1] Ivanov I.K. Gorlov K.A. A study of thermocatalytic transformations of solid fuels in the atmosphere of different gases // [J]. Solid fuel chemistry, 1997 (2) 45-62.

[2] Salamatova I.V., Vasiliev V.V., Potekhin V.M. Determination of autooxidation speed of some hydrocarbons and fuel oil residues // [J]. Petroleum refinery and petroleum chemistry, 2004 (8) 1622.

[3] Kotov S.V., Levanova S.V., Madumarova Z.R., Poguliayko V.A., Zinovieva L.V., Tyshchenko V.A. The influence of oxidation temperature on qualitative characteristics of road bitumen. // [J]. Petroleum chemistry, 1988 (5) 47-52.

[4] Rosental D.A. Improving the quality of construction bitumen. - M.: Central Scientific Research Institute of Information and Technical-Economic Research in Petroleum Refinery and Petroleum Chemistry, 1976.

[5] Begak O.Yu., Syroezhko A.M., Federov V.V. The distribution of elements by structural and group components of tars and bitumen from the inustrial West Siberian oil// [J].Magazine of applied chemistry, 2002 (75) 1201-1208.

[6] I.M. Rudenskaya, A.V. Rudenskiy. Rheological Properties of Bitumen. - M.: Higher School, 1967.

[7] A.I. Lyssikhina. Road Pavements and Bases Using Bitumen and Tars. - M.: Avtotransizdat, 1972. 